\title{
Sperm and seminal plasma RNAs: what roles do they play beyond fertilization?
}

\author{
Meritxell Jodar \\ Molecular Biology of Reproduction and Development Group, Fundació Clínic per a la Recerca Biomèdica, Institut \\ d'Investigacions Biomèdiques August Pi i Sunyer (IDIBAPS), Faculty of Medicine, University of Barcelona, \\ Barcelona, Spain
}

Correspondence should be addressed to M Jodar; Email: meritxell.jodar@ub.edu

\begin{abstract}
The paternal contribution to the new individual is not just limited to half the diploid genome. Recent findings have shown that sperm delivers to the oocyte several components, including a complex population of RNAs, which may influence early embryo development and the long-term phenotype of the offspring. Although the majority of sperm RNAs may only represent spermatogenic leftovers with no further function, the male gamete provides a specific set of RNAs to the oocyte that is able to modulate gene expression in the preimplantation embryo. Those sperm transcripts include coding and non-coding RNAs that might either be translated by the oocyte machinery or directly regulate embryo gene expression at the transcriptional or post-transcriptional level. Interestingly, some sperm RNAs seem to be acquired during post-testicular maturation through active communication between sperm and epididymal and seminal exosomes released by the epididymis and the male accessory sex glands, respectively. Exosomes contained in the seminal plasma seem to not only interact with the spermatozoa but also with cells from the female reproductive tract, modulating their gene expression and influencing female immune response triggered by the semen. This review also considers the findings that indicate the role of semen RNAs in preimplantation embryo development and offspring phenotypes. In this regard, different studies supporting the hypothesis of paternal epigenetic inheritance of altered metabolic phenotypes associated with environmental exposures are discussed. Lastly, potential mechanisms that could explain the impact of semen RNAs to both early embryogenesis and paternal epigenetic inheritance are suggested.

Reproduction (2019) 158 R113-R123
\end{abstract}

\section{Introduction}

Mature mammalian spermatozoa are thought to be transcriptionally and translationally inert, at least at the nuclear level. This general shutdown is the result of the events taking place during the last steps of the spermatogenesis, which include the reorganization and condensation of the chromatin through the progressive replacement of histones by transition proteins and then protamines, and the removal of most of the sperm cytoplasm (Oliva 2006). Despite the fact that transcriptional and translational processes are blocked and most of the RNAs are lost during cytoplasmic extrusion, a small but complex population of RNAs is non-randomly preserved in mature sperm (Jodar et al. 2013, Sendler et al. 2013, Gòdia et al. 2018a).

Infertility is a growing concern in human and animal reproductive health. The study of the sperm RNA profiles in both humans and domestic animals is currently providing the framework for the discovery of novel clinical biomarkers and potential diagnostic tools for fertility evaluation. For example, comparative analysis on human sperm RNA profiles has helped to delineate possible aberrant mechanisms underlying male infertility, revealing sperm molecular disturbances occurring during either spermatogenesis or sperm maturation (Platts et al. 2007, Jodar et al. 2012, Montjean et al. 2012). Moreover, human sperm RNAs might predict the success of specific assisted reproductive technologies (ART). This relies on the capacity of a set of $648 \mathrm{sperm}$ RNA elements (SREs) to discern idiopathic infertile patient groups according to the likelihood of achieving pregnancy using less invasive ART, such as intrauterine insemination (IUI) (Jodar et al. 2015). Male subfertility also has a high economic impact in the livestock industry since the animals selected on the basis of their pedigree or meat quality have a high variability in their ability to withstand cryopreservation (Vilagran et al. 2015) and in their breeding ability (Colenbrander et al. 2003, Khatun et al. 2013). This can have a dramatic impact on the general practice for using a single male to inseminate hundreds of females. Therefore, sperm RNA is emerging as a valuable tool that may help in the prediction of animal fertility and in the selection of the best male for future breeding, improving the cost-effectiveness of the 
livestock production (Fagerlind et al. 2015, Card et al. 2017, Suliman et al. 2018).

This review is focused on the composition of sperm RNAs in mammals, as well as on the impact of the secretions from the epididymis and the accessory sex glands on sperm RNA profiles. Although the most conservative perspective supports the view that sperm RNAs are just spermatogenic leftovers with no biological function in post-testicular events, growing evidence suggests that specific sperm RNAs might also be crucial beyond fertilization. Therefore, this review will discuss the most recent findings on the potential roles of semen RNA payload beyond fertilization.

\section{Sperm-borne RNAs}

Sperm RNA isolation is a challenging process that requires careful consideration of the following points: (i) one spermatozoon contains an exceptionally low quantity of RNA, which ranges from 10-50 fg in human sperm (Goodrich et al. 2013, Jodar et al. 2013), approximately $100 \mathrm{fg}$ in mice and rat sperm (Zhang et al. 2017), $20 \mathrm{fg}$ in stallion sperm (Das et al. 2010), 20-30 fg in bull sperm (Selvaraju et al. 2017) and 1-8fg in boar sperm (Gòdia et al. 2018b, Kasimanickam et al. 2019); (ii) the ejaculate frequently contains non-sperm contaminant cells with 100 times more RNA than sperm cells, which could mask the acquisition of accurate sperm RNA profiles by deep sequencing technologies and (iii) complete lysis of sperm is necessary to fully release the high proportion of RNAs embedded in the sperm nuclei (Johnson et al. 2015). However, the elevated level of disulfide bridges between protamines, which are the main DNA packaging proteins of the sperm nucleus, hinders the complete release of nucleic acids from sperm (Oliva 2006, Goodrich et al. 2013, Jodar \& Oliva 2014). Therefore, the addition of reducing agents such as beta-mercaptoethanol to lysis buffers is critical to isolate high-quality sperm RNA (Goodrich et al. 2013) and (iv) the sperm RNAs show an inherent high biological fragmentation that prevents the use of standard controls (RIN value, for example) for assessing sperm RNA quality (Johnson et al. 2011, Jodar et al. 2013, Sendler et al. 2013). Despite these limitations, several studies have contributed to the description of the landscape of spermatozoal RNAs revealing a complex and unique RNA population in the male gamete. This includes coding RNAs, long non-coding RNAs (IncRNAs) and small non-coding RNAs (sncRNAs) (Krawetz et al. 2011, Das et al. 2013, Jodar et al. 2013, 2015, Sendler et al. 2013, Pantano et al. 2015, Selvaraju et al. 2017, Zhang et al. 2017); all of them localized mainly in the sperm head (Johnson et al. 2015).

The use of RNA-sequencing technology (RNA-seq) in the study of spermatozoa has revealed that ribosomal RNAs (rRNAs) are the most abundant RNAs contained in sperm from human, pig, stallion and bull (around
$80 \%$ of total RNA), while in mice these rRNAs represent only $30 \%$ of total RNA (Das et al. 2013, Jodar et al. 2013, Johnson et al. 2015, Selvaraju et al. 2017, Gòdia et al. 2018a). rRNAs appear selectively cleaved in all these species, most probably to ensure the translational shutdown observed in mature sperm (Johnson et al. 2011, Das et al. 2013, Selvaraju et al. 2017). Similarly, a substantial proportion of fragmented coding RNAs have been detected, which suggests their presence in the mature sperm as simply persistent spermatogenic leftovers. However, the spermatozoon also contains intact transcripts, which may be selectively protected from degradation and it could be indicative of a crucial role beyond fertilization (Sendler et al. 2013, Selvaraju et al. 2017). Indeed, the most intact transcripts reveal ontologies related to mature spermatids, male infertility and early embryogenesis (Sendler et al. 2013). In this regard, a single reliable cross-species analysis conducted using a standardized sperm RNA isolation protocol has revealed a set of conserved coding sperm RNAs in four different mammalian species (that is human, mice, rat and rabbit), functionally related to developmental processes (Schuster et al. 2016).

The sperm cell also contains a large proportion of non-coding RNAs with potentially important biological functions (ENCODE Project Consortium 2012, Jodar et al. 2013). It is interesting to note, whereas some of the sperm long non-coding RNAs (>200nt) are also annotated in other cell types, a large number of sperm-specific non-coding RNAs have been identified, including intronic retained regions and short expression regions overlapping coding, intergenic or untranslated region (UTR) sequences (Fig. 1) (Jodar et al. 2013, Sendler et al. 2013, Selvaraju et al. 2017). Around 880 sperm IncRNAs seem to be conserved between human and mouse, but their roles in sperm function are unknown (Zhang et al. 2017).

Furthermore, $1 \%$ of sperm RNAs correspond to sncRNAs including repeat-associated small RNAs, micro(mi)RNA, tRNA-derived sncRNA (tRNA fragments), Piwi-interacting(piwi)RNA, small nucleolar RNAs, small nuclear RNAs, mitochondrial-derived small RNAs and YRNAs (Krawetz et al. 2011, Pantano et al. 2015, Schuster et al. 2016). Each subtype of sncRNAs differs in their biogenesis, length, roles and mechanisms to accomplish their likely biological function (Jodar et al. 2013, Gòdia et al. 2018b, Jodar \& Anton 2018). Of note, the interspecies comparison has revealed that miRNAs are the most conserved sncRNA population across species, with at least 67 miRNAs commonly identified in the male gamete from human, mice, rat and rabbit (Schuster et al. 2016).

\section{Seminal plasma RNAs}

Seminal plasma is a mixture of secretions from testes, epididymides and other accessory sex glands and its 

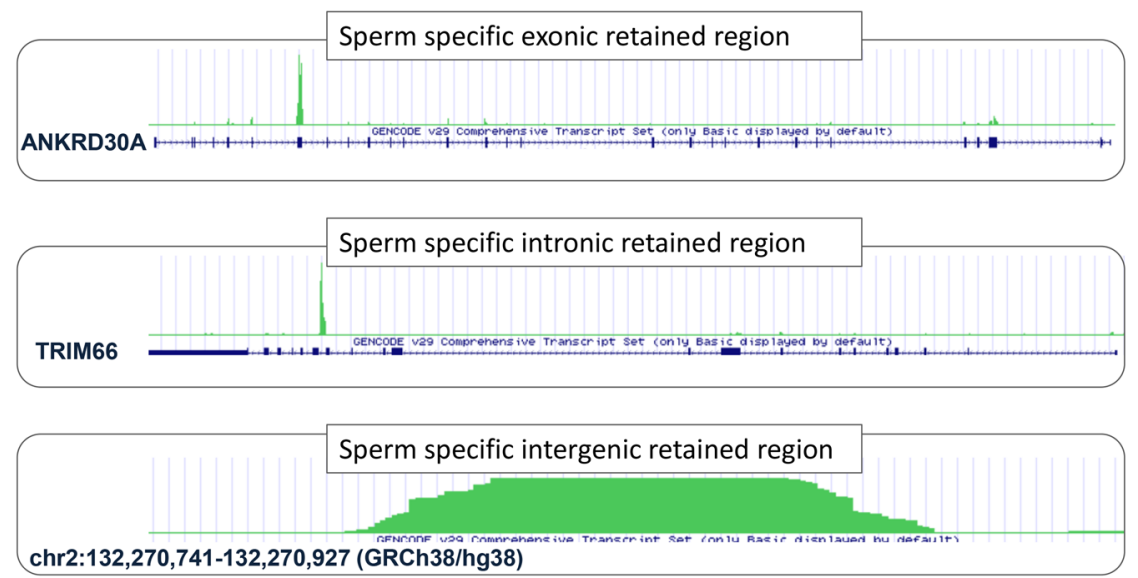

Figure 1 Sperm-specific long non-coding (lnc) RNAs. The sequence reads obtained from sperm RNA-seq data (green) corresponding to three sperm-specific IncRNAs are shown. The first and second boxes show two spermspecific IncRNAs, the first one located in the seventh exon (blue boxed of the gene representation) of the $A N K R D 30 A$ gene and the second one located in the sixth intron (blue line between two boxes of the gene representation) of the TRIM66 gene. In both examples, the levels of the specific exonic or intronic sperm RNAs are enhanced, whereas the coding regions of the corresponding transcripts are absent in sperm (note y-axis). The third example corresponds to a spermspecific IncRNAs located in an intergenic region from chromosome 2 not expressed in other tissues. composition varies among animal species. For example, human and mouse seminal plasma contains secretions mainly from seminal vesicles (70-80\% of the volume), and less from the prostate (20\%), epididymides - testes $(5 \%)$ and bulbourethral glands $(<1 \%)$ (Mcgraw et al. 2015). In contrast, the major contributors to boar seminal plasma are the prostate and the bulbourethral glands (Mcgraw et al. 2015). Secretions from the epididymides and accessory sex glands contain energy substrates, ions, proteins, RNAs and lipids, among others components, which could be found freely dissolved and in solution or encapsulated in extracellular vesicles or exosomes (Vojtech et al. 2014). There is increasing evidence showing that exosomes detected in different body fluids participate in intercellular communication, through the selective incorporation of their cargo into the target cell (Keerthikumar et al. 2016). Therefore, it seems obvious to think that the exosomes released by epididymides and accessory sex glands could play a role in the communication between seminal plasma and sperm. This functional involvement has been proposed for exosomes released by the epididymides (epididymosomes), which are capable of modifying the lipid composition of the sperm membrane, thus contributing both to the acquisition of sperm motility potential and to the ability to penetrate the zona pellucida (Sullivan \& Saez 2013). Additionally, many studies have shown the role of prostate-derived exosomes (prostasomes) in the stimulation of sperm motility while avoiding at the same time premature capacitation and spontaneous acrosome reaction (Aalberts et al. 2014). In addition, prostasomes have been found to be involved in the protection of the sperm against female immune response triggered in the female genital tract after contact with the semen (Aalberts et al. 2014).

As indicated above, transcripts retained in mature mammalian sperm are mainly remnants of untranslated mRNAs transcribed during the massive wave of transcription that takes place during the round spermatid stage before DNA compaction commences (SassoneCorsi 2002, Jodar et al. 2016). However, testicular and ejaculated sperm show distinct RNA profiles, since the germ cell RNA signature is subject to modification during sperm post-testicular maturation. It is well known that the mouse sperm sncRNAs profile is remodeled during epididymal transit with loss of piRNAs, a gain of tRNAs fragments and the acquisition and loss of specific sets of miRNAs (Nixon et al. 2015a, Conine et al. 2018, Sharma et al. 2018). Taking into consideration that the spermatozoon is a transcriptionally quiescent cell, the acquisition of new RNAs during the post-testicular maturation is ascribed to the active communication between the sperm and the epididymal fluid, most likely through the incorporation of RNAs contained in the epididymosomes (Belleannée et al. 2013, Sullivan \& Saez 2013, Sharma et al. 2016). It is interesting to note that not all the sncRNAs detected in sperm seem to have a testicular or epididymal origin, suggesting that the sperm could also incorporate exosomes released from other tissues (Nixon et al. 2015b). Although this hypothesis requires further experimental validation, a recent in silico analysis of the expression of human sperm proteins in tissues from the male reproductive tract and peripheral organs, at both transcriptomic and proteomic levels, supported a putative extra-testicular and extra-epididymal origin for some sperm proteins (Castillo et al. 2018).

However, since seminal plasma also interacts with the female reproductive tract, additional functions for its RNA have been proposed in addition to the regulation of sperm physiology. Seminal plasma is able to modulate ovulation in mammals including rabbits, cats and camels (Mcgraw et al. 2015), as well as the female immune response to the developing embryo (Robertson 2005, Watkins et al. 2018). Of note, exosomes contained in seminal plasma have 
been reported to increase the expression of immuneand inflammatory response-related genes in porcine endometrial tissue, reaching similar levels as those observed in the endometrium from naturally mated pigs (Bai et al. 2018). This suggests that communication between seminal plasma and the female reproductive tract could also be through the interaction with seminal exosomes.

A morecomprehensivestudy of the content of exosomes contained in the ejaculate is crucial to unraveling their potential functions in mammalian reproduction. To the best of our knowledge, only two studies have assessed the small RNA and long RNA content of ejaculatedderived exosomes by high-throughput technologies, respectively (Vojtech et al. 2014, Johnson et al. 2015). One the one hand, the assessment of small RNA profile has revealed that ejaculated-derived exosomes selectively retain several types of sncRNAs such as, from more to less abundance, miRNA, YRNAs, rRNA, tRNAs fragments, protein-coding derived sncRNAs and piRNAs (Vojtech et al. 2014). On the other hand, transcripts encoding for the sperm-specific protamines were detected among the 100 most abundant transcripts in the long RNA fraction from ejaculate-derived exosomes suggesting that sample contamination with sperm RNA remnants may have occurred (Johnson et al. 2015). This fact exposes technical limitations on exosome isolation strategies based only on differential centrifugation. The design of improved experimental approaches to obtain pure exosome populations from semen are needed to better characterize the RNA profile of exosomes released by epididymides and the accessory sex glands (Li et al. 2017).

\section{The role of semen RNAs beyond fertilization}

It is now broadly accepted that the male gamete is more than a vehicle for paternal DNA. The sperms' haploid genome includes DNA associated with different epigenetic marks and a complex population of proteins and RNAs that could be crucial for early embryogenesis and the future health of the offspring (Hammoud et al. 2009, Amaral et al. 2014, Carrell et al. 2016, Castillo et al. 2018). Additionally, although seminal plasma is not mandatory for successful reproduction, as reflected by positive outcomes of ART using testicular, epididymal and washed-ejaculated sperm, this fluid may also play a role in the embryo development and long-term health of the progeny (Robertson \& Sharkey 2016, Watkins et al. 2018). Specifically, it has been observed that the excision of the seminal vesicle glands in mice, which are the major contributors to the seminal plasma $(\sim 70 \%$ of volume), results in low pregnancy rates, placental hypertrophy and metabolic alterations in the offspring (Bromfield et al. 2014).

\section{Semen RNAs and early embryogenesis}

A critical role for sperm-borne RNAs on early embryogenesis is supported by studies conducted in mice (Table 1). In 2016, Yuan and colleagues observed that the reduction in the developmental potential of embryos generated with sperm containing disturbed sncRNAs profiles from testicular conditional knockouts of DICER and DROSHA were rescued by the injection of wild-type sperm RNAs (Yuan et al. 2016). Later on, Guo and colleagues observed reduced percentages of embryos reaching blastocyst stage and a lower ratio of live births when mature oocytes were injected with sperm containing 90\% less RNA than controls (Guo et al. 2017). These negative outcomes were partially rescued when total RNA from the wild-type sperm was injected into embryos derived from in vitro ART with RNA-deficient sperm (Guo et al. 2017).

Additionally, the importance of seminal plasmaderived sperm RNAs on early embryogenesis has also been demonstrated, at least in the mouse (Conine et al. 2018). Specifically, in comparison with embryos generated with testicular or cauda-epididymal sperm, mouse embryos generated with caput-epididymal sperm displayed reduced implantation rates and alterations on post-implantation development. Interestingly, these preimplantation molecular defects were completely rescued by the injection of sncRNAs with miRNAs-like sizes from cauda-derived epididymosomes (Conine et al. 2018). Therefore, in the mouse at least, epididymal sncRNAs seem to have roles in embryo implantation and post-implantation events. In addition, 100 miRNAs were underexpressed in epididymal caput sperm compared to the germ cells recovered from the epididymal cauda, suggesting differential regulation of their expression as the potential cause of the implantation defects observed on embryos generated with caput-epididymal sperm (Conine et al. 2018).

However, the role of the paternal RNAs in early embryogenesis seems to be not only restricted to the sperm RNAs delivered to the oocyte. Some reports suggest that sncRNAs encapsulated into the exosomes contained in semen could be delivered to acceptor cells from the female reproductive tract modulating their gene expression (Robertson \& Sharkey 2016, Bai et al. 2018). This modulation may contribute to the regulation of implantation or immune processes, both crucial for a successful pregnancy (Robertson \& Sharkey 2016). Although the ability of exosomal miRNAs to regulate gene expression in distant tissues has also been demonstrated in other systems (Thomou et al. 2017, Castaño et al. 2018), the regulatory effects of specific paternal exosomal RNAs on the female tract cells need to be experimentally demonstrated. 
Table 1 Summary of studies demonstrating the suggested role of paternal RNAs in early embryogenesis.

\begin{tabular}{|c|c|c|c|c|}
\hline Study & Experiment & Sperm RNA profile & Altered early embryogenesis & Conclusion \\
\hline \multicolumn{5}{|c|}{ Yuan et al. (2016) } \\
\hline & $\begin{array}{l}\text { Testicular conditional } \\
\text { DICER knockout }\end{array}$ & $\begin{array}{l}15 \% \text { miRNA upregulated } \\
\text { and } 32 \% \text { miRNAs } \\
\text { downregulated } \\
2 \% \text { endo-siRNAs } \\
\text { upregulated and } 6 \% \\
\text { endo-siRNAs } \\
\text { downregulated }\end{array}$ & $\begin{array}{l}\text { Embryos displayed significantly } \\
\text { reduced developmental } \\
\text { potential at } 2 \text { PN, 2-cell, 4-cell, } \\
\text { morula and blastocyst }\end{array}$ & \multirow[t]{2}{*}{$\begin{array}{l}\text { Developmental potential was rescued by } \\
\text { the injection of sperm RNAs or } \\
\text { sncRNAs from wild type reflecting the } \\
\text { importance of paternal miRNAs and } \\
\text { siRNAs in early embryo development }\end{array}$} \\
\hline & $\begin{array}{l}\text { Testicular conditional } \\
\text { DROSHA knockout }\end{array}$ & $\begin{array}{l}19 \% \text { miRNA upregulated } \\
\text { and } 37 \% \text { miRNAs } \\
\text { downregulated }\end{array}$ & $\begin{array}{l}\text { Embryos displayed significantly } \\
\text { reduced developmental } \\
\text { potential at 4-cell, morula and } \\
\text { blastocyst }\end{array}$ & \\
\hline \multicolumn{5}{|c|}{ Guo et al. (2017) } \\
\hline & $\begin{array}{l}\text { Spermatozoa were } \\
\text { treated with } \\
\text { lysolecithin, pronase } \\
\text { and RNases }\end{array}$ & $\begin{array}{l}\text { Sperm RNAs was } \\
\text { decreased by about } 90 \%\end{array}$ & $\begin{array}{l}\text { Reduced blastocyst formation } \\
\text { rate }\end{array}$ & $\begin{array}{l}\text { Developmental potential was rescued by } \\
\text { the injection of sperm RNAs from wild } \\
\text { type reflecting the importance of sperm } \\
\text { RNA including long and small in early } \\
\text { embryo development }\end{array}$ \\
\hline \multicolumn{5}{|c|}{ Conine et al. (2018) } \\
\hline & $\begin{array}{l}\text { ICSI using epididymal } \\
\text { sperm from caput and } \\
\text { epididymal sperm } \\
\text { from cauda }\end{array}$ & $\begin{array}{l}\text { High differences in sperm } \\
\text { small RNA payload } \\
\text { (piRNAs, tRNAs and } \\
\text { miRNAs) }\end{array}$ & $\begin{array}{l}\text { Multiple defects in post-implan- } \\
\text { tation development from } \\
\text { embryos derived from } \\
\text { epididymal caput sperm }\end{array}$ & $\begin{array}{l}\text { Developmental defects were rescued by } \\
\text { the injection of RNAd contained in the } \\
\text { epididymosomes isolated from the } \\
\text { cauda epididymis reflecting the } \\
\text { importance of sncRNAs gained during } \\
\text { epididymal transit in early } \\
\text { embryogenesis }\end{array}$ \\
\hline
\end{tabular}

WD, Western-like diet; HFD, high fat diet.

\section{Semen RNA and paternal epigenetic inheritance}

Several studies show that paternal preconception exposures, including paternal lifestyle, may be conditioning the health of future progeny. These include paternal age (Ramasamy et al. 2015), diet (Rando 2012, Schagdarsurengin \& Steger 2016), stress and habits such as smoking and alcohol consumption (Finegersh et al. 2015, Esakky \& Moley 2016). Interestingly, it has been proposed that alterations in gene expression during early embryo development can induce these longlasting effects. Some of the known epigenetic factors able to modify gene expression are (i) DNA methylation and hydroxymethylation marks, (ii) post-translational modifications (PTMs) of histones, (iii) non-coding RNAs and (iv) proteins that could modulate gene expression by the direct regulation of transcription or through the modulation of other epigenetic marks. In the sperm cell, the aforementioned marks could act as potential carriers for the epigenetic information by which the male can influence progeny phenotypes (Zeybel et al. 2012, Vassoler et al. 2013, Castillo et al. 2018).

Growing evidence points to a role for sperm sncRNAs in the phenotypic variations reflective of paternal life experiences (Rodgers et al. 2013, Gapp et al. 2014, Grandjean et al. 2015, Chen et al. 2016a,b, Sharma et al. 2016, Jodar \& Anton 2018). In particular, it has been shown that the injection of total or specific sperm miRNAs and tRNA fragments from males exposed to highfat diet (HFD) or mental stress into zygotes that were not exposed to these stressors, achieves the recapitulation of those associated altered phenotypes (Rassoulzadegan et al. 2006, Gapp et al. 2014, Grandjean et al. 2015, Chen et al. 2016b, Sharma et al. 2016). However, these microinjection experiments were unable to recapitulate all phenotypic traits observed in natural offspring from exposed fathers (Table 2). For example, the progeny of male mice reared under western diet-based chow (WD) exhibited increased body weight, altered fasting blood glucose and more hyperglycemia in response to both glucose and insulin injections. However, the microinjection of miR-19, a differentially expressed sperm miRNA in the WD group, into a wild-type zygote resulted in individuals with increased body weight but not glucose metabolic alterations (Grandjean et al. 2015). The partial recapitulation of the phenotypes by microinjection experiments (Table 2) suggests the involvement of additional sperm factors on the transmission of phenotypic alterations linked to paternal exposures. In this regard, long RNAs including coding mRNAs and IncRNAs have also been proposed as potential vehicles for paternal epigenetic inheritance. In fact, it has been observed that the injection of either the small or the long RNA fraction into wild-type oocytes recapitulates different hallmarks of the phenotype observed in offspring of males exposed to postnatal trauma (Gapp et al. 2018). Different RNA types may, therefore, be able to trigger specific phenotypic traits (Table 2).

The extra-testicular origin of some sperm sncRNAs is implicated in paternal epigenetic inheritance, which might be absorbed and incorporated into sperm via epididymosomes during sperm maturation or in semen 
Table 2 Summary of studies assessing epigenetic inheritance of altered phenotypes associated with a paternal exposure by the male germline including study, species, paternal exposure and offspring phenotype (F1) observed after both natural mating and microinjection experiments.

\begin{tabular}{|c|c|c|c|c|}
\hline \multirow[b]{2}{*}{ Study } & \multirow[b]{2}{*}{ Species } & \multirow[b]{2}{*}{$\begin{array}{l}\text { Paternal } \\
\text { exposure }\end{array}$} & \multicolumn{2}{|c|}{ Altered phenotypic traits in offspring (F1) } \\
\hline & & & $\begin{array}{l}\text { Natural mating or ICSI procedures } \\
\text { with males under the paternal exposure }\end{array}$ & RNA injection experiments \\
\hline $\begin{array}{l}\text { Gapp et al. } \\
(2014)\end{array}$ & $\begin{array}{l}\text { Mice } \\
\text { C57Bl/6 }\end{array}$ & $\begin{array}{l}\text { Traumatic } \\
\text { stress in } \\
\text { early life }\end{array}$ & $\begin{array}{l}\text { Reduced avoidance and fear, altered } \\
\text { response to aversive conditions, } \\
\text { depressive-like behaviors, insulin } \\
\text { hypersensitivity, hypermetabolism }\end{array}$ & $\begin{array}{l}\text { Sperm RNA (male under early traumatic stress) } \\
\text { injection: Comparable behavioral, metabolic and } \\
\text { molecular effects }\end{array}$ \\
\hline $\begin{array}{l}\text { Grandjean et al. } \\
(2015)\end{array}$ & $\begin{array}{l}\text { Mice } \\
\text { C57Bl/6 }\end{array}$ & WD & $\begin{array}{l}\text { Increased body weight, altered fasting } \\
\text { blood glucose and higher glycemia in } \\
\text { response to both glucose and insulin }\end{array}$ & $\begin{array}{l}\text { Sperm RNA (male under WD) injection: Increased } \\
\text { body weight and higher glycemia in response to } \\
\text { both glucose and insulin } \\
\text { miR19b injection: Increased body weight } \\
\text { miR29 injection: - }\end{array}$ \\
\hline $\begin{array}{l}\text { Chen et al. } \\
(2016 a, b)\end{array}$ & $\begin{array}{l}\text { Mice } \\
\text { C57BI/6 }\end{array}$ & HFD & $\begin{array}{l}\text { Impaired glucose tolerance and insulin } \\
\text { resistance }\end{array}$ & $\begin{array}{l}\text { Sperm RNA (male under HFD) injection: Impaired } \\
\text { glucose tolerance } \\
\text { Small RNAs ( } 15-25 \mathrm{nt} \text {, males under HFD) } \\
\text { injection: - } \\
\text { Small RNAs ( } 30-40 \mathrm{nt} \text {, males under HFD) injection: } \\
\text { Impaired glucose tolerance } \\
\text { Small RNAs (>40 nt, males under HFD) injection:- } \\
\text { Synthetic tRNA fragments: - }\end{array}$ \\
\hline $\begin{array}{l}\text { Gapp et al. } \\
\text { (2018) }\end{array}$ & $\begin{array}{l}\text { Mice } \\
\text { C57Bl/6 }\end{array}$ & $\begin{array}{l}\text { Traumatic } \\
\text { stress in } \\
\text { early life }\end{array}$ & $\begin{array}{l}\text { Reduced avoidance and fear, altered } \\
\text { response to aversive conditions, } \\
\text { depressive-like behaviors, insulin } \\
\text { hypersensitivity, hypermetabolism }\end{array}$ & $\begin{array}{l}\text { Sperm small RNA (male under early traumatic } \\
\text { stress) injection: Changes in locomotor activity not } \\
\text { observed by natural mating } \\
\text { Sperm long RNA (male under early traumatic } \\
\text { stress) injection: altered response to aversive } \\
\text { conditions, insulin hypersensitivity, } \\
\text { hypermetabolism }\end{array}$ \\
\hline
\end{tabular}

(Chen et al. 2016b, Sharma et al. 2016). This strategy could permit the transfer of epigenetic information about the paternal environment to the new individual without the need to overcome the blood-testis barrier or be incorporated into the germ line during spermatogenesis per se.

Despite experimental evidence supporting the transmission of phenotypic alterations associated with paternal exposures, one of the major concerns surrounding an RNA-mediated epigenetic inheritance by the paternal germ line is the incomplete penetrance observed (Huypens et al. 2016). Indeed, several examples of this phenomenon have been reported in the literature showing that the response of male animals to environmental exposures varies widely even among the individual cohorts (Dias \& Ressler 2014, Gapp et al. 2014, Huypens et al. 2016). For example, only approximately $15 \%$ of the female progeny of male mice raised under HFD exhibited extreme obesity, with approximately $65 \%$ showing similar body weights to that observed in the control group (Huypens et al. 2016). This incomplete penetrance could reflect the heterogeneity of sperm epigenetic marks, such as a different RNA content between sperm from the same ejaculate. Sperm single-cell RNA-seq data might clarify this hypothesis.

\section{Mechanisms underlying semen RNA function in the early embryo}

The molecular mechanisms underlying semen RNA function in the earlyembryo remain unclear. Nevertheless, it is important to bear in mind that whereas changes at the (sperm) chromatin level may not be detected before the activation of the embryonic genome, alterations in the sperm RNA profile could induce preimplantation effects as early as the 1-cell zygote stage. Here, two potential modes of action for semen RNAs during preimplantation embryo development are proposed: (i) the translation of intact sperm-coding mRNAs using the zygote translational machinery provided by the oocyte and (ii) the regulation of embryo gene expression by sperm-borne non-coding RNAs (Miller 2015, Ntostis et al. 2017).

Intact sperm mRNAs could be translated in early embryogenesis using the zygote translational machinery provided by the oocyte

It is well known that the injection of phospholipase Cz1 (P/CZ1) transcripts into a mouse oocyte induces its translation and, therefore, oocyte activation (Yoda et al. 2004). These findings have raised the possibility for the potential translation of sperm-borne coding mRNAs by the oocyte machinery (Ntostis et al. 2017). Supporting this hypothesis, we recently undertook an integrative analysis of transcriptomic and proteomic data from human sperm, oocytes and early embryos, which revealed 11 blastocyst proteins most likely originating from the translation of sperm RNAs during early embryogenesis (Table 3; Castillo et al. 2018). In particular, these 11 human blastocyst proteins were not detected in the proteomic profile of sperm, oocyte and 
Table 3 Potential blastocyst proteins originated by the translation of sperm RNAs in early embryo.

\begin{tabular}{|c|c|c|c|c|c|c|c|c|c|}
\hline \multirow[b]{2}{*}{ Gene ID } & \multirow[b]{2}{*}{ Proteomic data } & \multicolumn{8}{|c|}{ RNA-seq data (FPKM values) } \\
\hline & & Sperm & Oocyte & Zygote & 2-Cell & 4-Cell & 8-Cell & Morula & Blastocyst \\
\hline ANKRD12 & Blastocyst & 30.59 & 3.81 & 1.56 & 0.83 & 5.33 & 2.80 & 1.60 & 1.89 \\
\hline ARHGAP26 & Blastocyst & 26.51 & 9.67 & 7.21 & 5.08 & 2.34 & 1.32 & 0.51 & 0.92 \\
\hline ATP7B & Blastocyst & 25.51 & 3.99 & 2.31 & 1.87 & 0.22 & 0.13 & 0.09 & 3.04 \\
\hline$B B X$ & Blastocyst & 65.19 & 0.34 & 0.16 & 0.07 & 1.56 & 2.37 & 1.49 & 2.09 \\
\hline CYP2R1 & Blastocyst & 25.68 & 2.11 & 2.81 & 0.72 & 1.01 & 2.38 & 0.53 & 0.11 \\
\hline FGD4 & Blastocyst & 60.71 & 7.02 & 4.61 & 3.28 & 1.04 & 0.94 & 1.36 & 2.24 \\
\hline KIAA0586 & Blastocyst & 25.25 & 9.76 & 8.05 & 5.19 & 1.67 & 2.46 & 0.93 & 4.02 \\
\hline RASSF8 & Blastocyst & 39.79 & 8.25 & 6.32 & 4.48 & 2.90 & 3.92 & 3.30 & 1.44 \\
\hline SIPA $1 L 3$ & Blastocyst & 25.48 & 2.50 & 0.43 & 0.58 & 0.12 & 0.32 & 0.11 & 0.20 \\
\hline SPIRE1 & Blastocyst & 50.52 & 7.53 & 5.23 & 3.29 & 0.59 & 0.51 & 0.39 & 4.50 \\
\hline ZNF646 & Blastocyst & 34.47 & 1.98 & 1.23 & 1.81 & 0.28 & 0.58 & 0.41 & 0.58 \\
\hline
\end{tabular}

A total of 11 blastocyst proteins were classified as paternally derived due to their exclusively presence in blastocyst proteome and their corresponding RNAs detected solely in sperm RNA-seq dataset (values over 25FPKM).

any other embryo-related cells and fluids, such as the cumulus cells and the follicular and endometrial fluids. However, their corresponding RNAs were detected with high abundance in spermatozoa (>25 FPKM), very low abundance in the oocyte $(<10$ FPKM) and gradual decreasing levels in the different stages of the preimplantation embryo, even after the activation of the genome (Table 3). The fact that the transcription of the human embryo genome is shut down until it reaches the four-cell stage, combined with the absence of this set of proteins and their corresponding RNAs in the oocyte leads to the proposition that the translation of these 11 coding transcripts in the preimplantation embryo was accomplished after being delivered by sperm. Blastocyst proteins potentially derived from sperm RNAs include transcript factors, such as the BBX, the HMGbox containing (BBX) and the zinc finger protein 646 (ZNF646), as well as histone modifiers, such as the Ankyrin repeat domain 12 (ANKRD12), which might be able to regulate gene expression once the zygote genome is activated. Additionally, some of these sperm RNAs encode for proteins that regulate the activity of GTPases that may be essential for the cytoskeleton dynamics during early embryo development (Duquette \& Vane 2014) including the Rho GTPase-activating protein 26 (ARHGAP26), the FYVE, RhoGEF And PH domain containing 4 (FGD4) and the signal induced proliferation associated 1 like 3 (SIPA1L3). Finally, the blastocyst centrosomal protein KIAA0586, specific depletion of which in mice leads to embryos with abnormal left-right axis patterning (Bangs et al. 2011), has also been predicted as paternally derived.

Similar studies in mice suggested that sperm mRNAs most likely translated in the zygote might complement maternal cofactors or pathways required for maternal RNA clearance during the egg-to-zygote transition, acting as a checkpoint to start the activation of the embryonic genome (Ntostis et al. 2017). Furthermore, other proteins crucial for murine early embryogenesis such as the Wnt family member 4 (WNT4) protein has been predicted to be paternally derived as a result of sperm RNA translation in the zygote. (Fang et al. 2014). Further experimental data are required to validate the impact of these paternally derived RNAs and proteins during preimplantation embryogenesis.

\section{Sperm-borne non-coding RNAs regulate gene expression in the early embryo}

The participation of non-coding RNAs in the modulation of gene expression at either the transcriptional or posttranscriptional level is well established in different tissues and systems. For example, miRNAs and tRNA fragments are able to regulate mRNA degradation and/or translational repression in a sequence-specific manner through complementary sequences on either the $3^{\prime}$-UTR or 5'-UTR regions of transcripts, respectively (Schuster et al. 2016). Additionally, non-coding RNAs including sncRNAs and IncRNA show specific nuclear functions such as the regulation of both activation and inhibition of transcription, mRNA splicing, DNA methylation, histone modifications and chromatin conformation (Jodar et al. 2013, Liebers et al. 2014, Catalanotto et al. 2016).

Although the quantity of sperm RNAs released into the oocyte is minimal compared to the oocyte reservoir, small biases in particular ncRNAs could impact on the expression of several genes at the same time in a cascade-like fashion, at transcriptional and/or posttranscriptional level (Chen et al. 2016a). Supporting this hypothesis, it has been observed that the injection of tRNA-Gly fragments (one of the upregulated sperm sncRNAs by a low-protein diet) into zygotes represses MERVL-regulated transcripts in two-cell embryos and slows down the development of the embryo compared to controls (Sharma et al. 2016). At this point, however, it is not possible to discern if the altered metabolic phenotype associated with paternal diet is the result of altered preimplantation growth kinetics or the regulation of MERVL targets.

Additionally, single-cell RNA-seq from embryos generated using sperm from the epididymal caput or cauda revealed differences in the expression of RNA- 
binding proteins and chromatin modifiers from the two-cell to the blastocyst stage (Sharma et al. 2018). However, the regulatory networks taking place in the potential regulation of embryonic gene expression by sperm RNA remain to be elucidated.

\section{New horizons}

Early stages of embryogenesis may not be under the sole control of the oocyte cytoplasm, since sperm also contribute, although to a lesser extent, components such as RNAs. Research in the reproductive field has been focused mainly on the biology of the gametes. However, growing evidence shows that seminal plasma and its constituent RNAs (including RNAs of epididymal origin) is not just a transport medium for sperm, but is probably also important for sperm function, fertilization, early embryogenesis and even for the modulation of the offspring phenotype (at least in the murine model).

Paternal RNAs could be classified according to their transcriptional origin in: (i) RNAs transcribed in testes selectively retained in sperm, (ii) sperm RNAs with an extra-testicular origin that are acquired by the spermatozoa from exosomes released by epididymides or accessory sex glands during sperm maturation and (iii) RNAs with an extra-testicular origin encapsulated in exosomes contained in the semen that interact directly to female tract (Fig. 2). If sperm RNAs are crucial for early embryogenesis and do act as epigenetic carriers of external and environmental information, then one of the biggest concerns we may face, particularly in the era of ART is that the RNA molecule is labile and easily degraded. For this reason, the acquisition and use of RNAs from secretions of the accessory sex glands could be a good strategy to preserve the sperm transcriptomic profile under optimal conditions for subsequent support of early embryogenesis. However, sperm are susceptible to damage during their long journey to reach the oocyte, suggesting that additional steps to guarantee the stability of the RNAs may also be required.

RNA modifications such as the addition of a methylcytidine (m5C) or N2-methylguanosine (m2G) contribute to tRNA stability (Tuorto et al. 2015). The participation of these RNA modifications in the paternal epigenetic inheritance was proposed when the injection of synthetic tRNAs fragments into normal oocytes was not able to recapitulate the altered metabolic phenotype in the same way as native sperm tRNAs fragments (Table 2; Chen et al. 2016b). Whereas sperm tRNAs fragments harbor several modifications, the absence of such modifications in the synthetic tRNAs was associated with their rapid degradation upon the spermoocyte fusion.

There are other hypothetical mechanisms that could explain the stability of paternal RNAs during early embryogenesis, but none of them have been experimentally tested so far. One mechanism is associated with the reported ability of sperm to reverse-transcribe exogenous RNAs to cDNA by reverse transcriptase (RT) activity encoded by LINE-1 retrotransposons (Spadafora 2017). cDNA molecules show higher stability than RNAs and could arrive in the oocyte under optimal

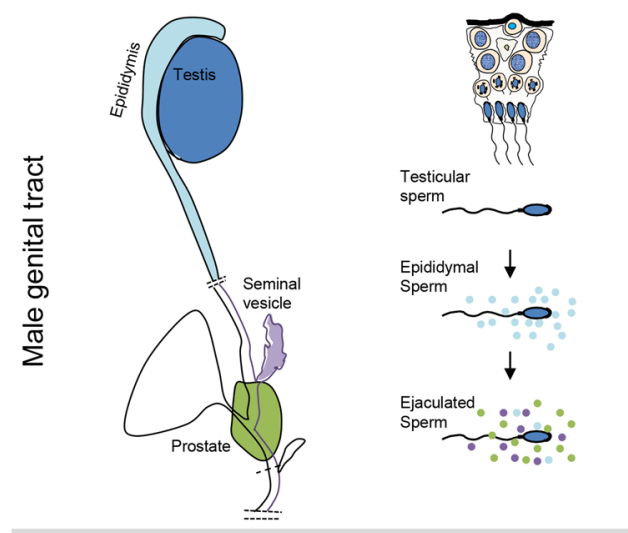

Ejaculation

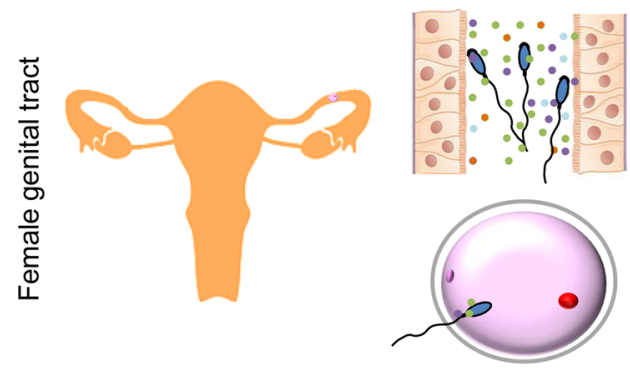

Reproduction (2019) 158 R113-R123
Testicular RNAs retained in sperm

During epididymal transit sperm RNA profile is remodeled most probably by the contact of sperm with epididymosomes (loss of piRNAs, gain of tRNAs fragments and changes in miRNA profile)

During ejaculation sperm enter in contact with exosomes released by accessory sex glands and sperm could incorporate RNAs (Requires experimental validation)

RNAs from exosomes contained in seminal plasma could be incorporated in epithelial cells of female tract and modulate their gene expression (Requires experimental validation)

Sperm coding RNAs could be translated in oocyte and in conjunction with sperm non-coding RNAs modulate embryonic gene expression.
Figure 2 Dynamics of semen RNA profile through male and female genital tract. All RNAs contained in testicular sperm are untranslated RNAs transcribed during the spermatogenesis in testes. Testicular sperm initiates then a maturation process through it transit in the epididymis. During sperm maturation in the epididymis, testicular sperm enter in contact with the epididymal fluid and some epididymal RNAs are incorporated into sperm through sperm-exosomes communication. Similarly, during ejaculation sperm could acquire RNAs encapsulated in exosomes released by other accessories glands such as prostate and seminal vesicles. Once semen is deposited to female tract, seminal exosomes might interact with epithelial cells from the female leading to the possible acquisition of paternal RNAs. At the same time, epithelial cells from female tract also are able to release exosomes that could provide maternal RNAs to sperm. Finally, a spermatozoon capable to reach the oocyte provides all the RNAs with different transcriptional origins to the zygote. 
conditions to carry out their functions. Another potential mechanism could involve the participation of circRNAs, a new type of ncRNAs which is more stable than the linear RNAs (Szabo \& Salzman 2016). Although natural circRNAs are not translated, several regulatory roles at both transcriptional and post-transcriptional levels have been ascribed to them, such as the modulation of the RNA polymerase II activity, the regulation of alternative splicing or the sponging of miRNAs and other factors such as RNA-binding proteins or ribonucleoproteins complex (RNPs) (Memczak et al. 2013, 2015). The potential regulatory functions ascribed to circRNAs in conjunction with their remarkable stability with halflives exceeding $48 \mathrm{~h}$ (Jeck et al. 2013) suggests that this new type of non-coding RNAs could be self-protecting themselves or protecting other sperm RNAs from degradation during their long sperm-borne journey to the oocyte.

\section{Conclusions}

The majority of the paternal RNAs are unlikely to have a post-testicular role, and probably only represent the residue from spermatogenesis and sperm maturation, making them potentially useful as biomarkers of male fertility. However, there is a subset of specific sperm RNAs that could play a role in early embryogenesis, as demonstrated by microinjection experiments. These paternal RNAs may regulate events both prior to the synthesis of embryonic gene products and beyond zygotic genome activation. Additionally, it has been proposed that RNAs from seminal exosomes could regulate gene expression in cells within female genital tract, probably by modulating critical events for the pregnancy success, including the female immune response and embryo implantation (Fig. 2). However, further experimental data are required to validate these hypotheses.

\section{Declaration of interest}

The author declares that there is no conflict of interest that could be perceived as prejudicing the impartiality of this review.

\section{Funding}

M J is granted by Government of Catalonia (Generalitat de Catalunya, pla Estratègic de Recerca i Innovació en Salut, PERIS 2016-2020, SLT002/16/00337).

\section{Acknowledgments}

I greatly thank Dr Judit Castillo for critical revision of the manuscript.

\section{References}

Aalberts M, Stout TAE \& Stoorvogel W 2014 Prostasomes: extracellular vesicles from the prostate. Reproduction 147 R1-R14. (https://doi. org/10.1530/REP-13-0358)

Amaral A, Castillo J, Ramalho-Santos J \& Oliva R 2014 The combined human sperm proteome: cellular pathways and implications for basic and clinical science. Human Reproduction Update 20 40-62. (https:// doi.org/10.1093/humupd/dmt046)

Bai R, Latifi Z, Kusama K, Nakamura K, Shimada M \& Imakawa K 2018 Induction of immune-related gene expression by seminal exosomes in the porcine endometrium. Biochemical and Biophysical Research Communications 495 1094-1101. (https://doi.org/10.1016/j. bbrc.2017.11.100)

Bangs F, Antonio N, Thongnuek P, Welten M, Davey MG, Briscoe J \& Tickle C 2011 Generation of mice with functional inactivation of talpid3, a gene first identified in chicken. Development 138 3261-3272. (https:// doi.org/10.1242/dev.063602)

Belleannée C, Calvo É, Caballero J \& Sullivan R 2013 Epididymosomes convey different repertoires of microRNAs throughout the bovine epididymis. Biology of Reproduction 89 30. (https://doi.org/10.1095/ biolreprod.113.110486)

Bromfield JJ, Schjenken JE, Chin PY, Care AS, Jasper MJ \& Robertson SA 2014 Maternal tract factors contribute to paternal seminal fluid impact on metabolic phenotype in offspring. PNAS 111 2200-2205. (https://doi. org/10.1073/pnas.1305609111)

Card CJ, Krieger KE, Kaproth M \& Sartini BL 2017 Oligo-dT selected spermatozoal transcript profiles differ among higher and lower fertility dairy sires. Animal Reproduction Science 177 105-123. (https://doi. org/10.1016/j.anireprosci.2016.12.011)

Carrell DT, Aston KI, Oliva R, Emery BR \& De Jonge CJ 2016 The 'omics' of human male infertility: integrating big data in a systems biology approach. Cell and Tissue Research 363 295-312. (https://doi. org/10.1007/s00441-015-2320-7)

Castaño C, Kalko S, Novials A \& Párrizas M 2018 Obesity-associated exosomal miRNAs modulate glucose and lipid metabolism in mice. PNAS 115 12158-12163. (https://doi.org/10.1073/pnas.1808855115)

Castillo J, Jodar M \& Oliva R 2018 The contribution of human sperm proteins to the development and epigenome of the preimplantation embryo. Human Reproduction Update 24 535-555. (https://doi. org/10.1093/humupd/dmy017)

Catalanotto C, Cogoni C \& Zardo G 2016 MicroRNA in control of gene expression: an overview of nuclear functions. International Journal of Molecular Sciences 17 E1712. (https://doi.org/10.3390/ijms17101712)

Chen Q, Yan W \& Duan E 2016 a Epigenetic inheritance of acquired traits through sperm RNAs and sperm RNA modifications. Nature Reviews: Genetics 17 733-743. (https://doi.org/10.1038/nrg.2016.106)

Chen Q, Yan M, Cao Z, Li X, Zhang Y, Shi J, Feng GH, Peng H, Zhang X, Zhang Y et al. 2016b Sperm tsRNAs contribute to intergenerational inheritance of an acquired metabolic disorder. Science 351 397-400. (https://doi.org/10.1126/science.aad7977)

Colenbrander B, Gadella BM \& Stout TAE 2003 The predictive value of semen analysis in the evaluation of stallion fertility. Reproduction in Domestic Animals 38 305-311. (https://doi.org/10.1046/j.14390531.2003.00451.x)

Conine CC, Sun F, Song L, Rivera-Pérez JA \& Rando OJ 2018 Small RNAs gained during epididymal transit of sperm are essential for embryonic development in mice. Developmental Cell 46 470.e3-480.e3. (https:// doi.org/10.1016/j.devcel.2018.06.024)

ENCODE Project Consortium 2012 An integrated encyclopedia of DNA elements in the human genome. Nature 489 57-74. (https://doi. org/10.1038/nature11247)

Das PJ, Paria N, Gustafson-Seabury A, Vishnoi M, Chaki SP, Love CC, Varner DD, Chowdhary BP \& Raudsepp T 2010 Total RNA isolation from stallion sperm and testis biopsies. Theriogenology 74 1099.e1-1106.e1. (https://doi.org/10.1016/j.theriogenology.2010.04.023)

Das PJ, McCarthy F, Vishnoi M, Paria N, Gresham C, Li G, Kachroo P, Sudderth AK, Teague S, Love CC et al. 2013 Stallion sperm transcriptome comprises functionally coherent coding and regulatory RNAs as revealed by microarray analysis and RNA-seq. PLOS ONE 8 e56535. (https://doi. org/10.1371/journal.pone.0056535) 
Dias BG \& Ressler KJ 2014 Parental olfactory experience influences behavior and neural structure in subsequent generations. Nature Neuroscience 17 89-96. (https://doi.org/10.1038/nn.3594)

Duquette PM \& Vane NL 2014 Rho GTPases in embryonic development. Small GTPases 5 8. (https://doi.org/10.4161/sgtp.29716)

Esakky P \& Moley KH 2016 Paternal smoking and germ cell death: a mechanistic link to the effects of cigarette smoke on spermatogenesis and possible long-term sequelae in offspring. Molecular and Cellular Endocrinology $435 \quad 85-93 . \quad$ (https://doi.org/10.1016/j. mce.2016.07.015)

Fagerlind M, Stålhammar H, Olsson B \& Klinga-Levan K 2015 Expression of miRNAs in bull spermatozoa correlates with fertility rates. Reproduction in Domestic Animals 50 587-594. (https://doi.org/10.1111/rda.12531)

Fang P, Zeng P, Wang Z, Liu M, Xu W, Dai J, Zhao X, Zhang D, Liang D, Chen X et al. 2014 Estimated diversity of messenger RNAs in each murine spermatozoa and their potential function During early zygotic development. Biology of Reproduction 90 94. (https://doi.org/10.1095/ biolreprod.114.117788)

Finegersh A, Rompala GR, Martin DIK \& Homanics GE 2015 Drinking beyond a lifetime: new and emerging insights into paternal alcohol exposure on subsequent generations. Alcohol 49 461-470. (https://doi. org/10.1016/j.alcohol.2015.02.008)

Gapp K, Jawaid A, Sarkies P, Bohacek J, Pelczar P, Prados J, Farinelli L, Miska E \& Mansuy IM 2014 Implication of sperm RNAs in transgenerational inheritance of the effects of early trauma in mice. Nature Neuroscience 17 667-669. (https://doi.org/10.1038/nn.3695)

Gapp K, van Steenwyk G, Germain PL, Matsushima W, Rudolph KLM, Manuella F, Roszkowski M, Vernaz G, Ghosh T, Pelczar P et al. 2018 Alterations in sperm long RNA contribute to the epigenetic inheritance of the effects of postnatal trauma. Molecular Psychiatry Epub.. (https:// doi.org/10.1038/s41380-018-0271-6)

Gòdia M, Mayer FQ, Nafissi J, Castelló A, Rodríguez-Gil JE, Sánchez A \& Clop A 2018a A technical assessment of the porcine ejaculated spermatozoa for a sperm-specific RNA-seq analysis. Systems Biology in Reproductive Medicine 64 291-303. (https://doi.org/10.1080/1939636 8.2018.1464610)

Gòdia M, Swanson G \& Krawetz SA $2018 b$ A history of why fathers' RNA matters. Biology of Reproduction 99 147-159. (https://doi.org/10.1093/ biolre/ioy007)

Goodrich RJ, Anton E \& Krawetz SA 2013 Isolating MRNA and small noncoding RNAs from human sperm. Methods in Molecular Biology 927 385-396. (https://doi.org/10.1007/978-1-62703-038-0_33)

Grandjean V, Fourré S, De Abreu DAF, Derieppe MA, Remy JJ \& Rassoulzadegan M 2015 RNA-mediated paternal heredity of dietinduced obesity and metabolic disorders. Scientific Reports 518193. (https://doi.org/10.1038/srep18193)

Guo L, Chao SB, Xiao L, Wang ZB, Meng TG, Li YY, Han ZM, Ouyang YC, Hou Y, Sun QY et al. 2017 Sperm-carried RNAs play critical roles in mouse embryonic development. Oncotarget 8 67394-67405. (https:// doi.org/10.18632/oncotarget.18672)

Hammoud SS, Nix DA, Zhang H, Purwar J, Carrell DT \& Cairns BR 2009 Distinctive chromatin in human sperm packages genes for embryo development. Nature 460 473-478. (https://doi.org/10.1038/ nature08162)

Huypens P, Sass S, Wu M, Dyckhoff D, Tschöp M, Theis F, Marschall S, de Angelis MH \& Beckers J 2016 Epigenetic germline inheritance of dietinduced obesity and insulin resistance. Nature Genetics 48 497-499. (https://doi.org/10.1038/ng.3527)

Jeck WR, Sorrentino JA, Wang K, Slevin MK, Burd CE, Liu J, Marzluff WF \& Sharpless NE 2013 Circular RNAs are abundant, conserved, and associated with ALU repeats. RNA 19 141-157. (https://doi.org/10.1261/ rna.035667.112)

Jodar M \& Anton E 2018 In Small RNAs Present in Semen and Their Role in Reproduction, Chapter 7, pp 109-123. Eds JA Horcajadas and JBT-R Gosálvez. Academic Press. (https://doi.org/10.1016/B978-0-12-8125717.00008-3)

Jodar M \& Oliva R 2014 Protamine alterations in human spermatozoa. Advances in Experimental Medicine and Biology 791 83-102. (https:// doi.org/10.1007/978-1-4614-7783-9_6)

Jodar M, Kalko S, Castillo J, Ballescà JL \& Oliva R 2012 Differential RNAs in the sperm cells of asthenozoospermic patients. Human Reproduction 27 1431-1438. (https://doi.org/10.1093/humrep/des021)
Jodar M, Selvaraju S, Sendler E, Diamond MP, Krawetz SA \& Reproductive Medicine Network 2013 The presence, role and clinical use of spermatozoal RNAs. Human Reproduction Update 19 604-624. (https:// doi.org/10.1093/humupd/dmt031)

Jodar M, Sendler E, Moskovtsev SI, Librach CL, Goodrich R, Swanson S, Hauser R, Diamond MP \& Krawetz SA 2015 Absence of sperm RNA elements correlates with idiopathic male infertility. Science Translational Medicine 7 295re6. (https://doi.org/10.1126/scitranslmed.aab1287)

Jodar M, Sendler E \& Krawetz SA 2016 The protein and transcript profiles of human semen. Cell and Tissue Research 363 85-96. (https://doi. org/10.1007/s00441-015-2237-1)

Johnson GD, Sendler E, Lalancette C, Hauser R, Diamond MP \& Krawetz SA 2011 Cleavage of rRNA ensures translational cessation in sperm at fertilization. Molecular Human Reproduction 17 721-726. (https://doi.org/10.1093/molehr/gar054)

Johnson GD, Mackie P, Jodar M, Moskovtsev S \& Krawetz SA 2015 Chromatin and extracellular vesicle associated sperm RNAs. Nucleic Acids Research 43 6847-6859. (https://doi.org/10.1093/nar/gkv591)

Kasimanickam V, Buhr M \& Kasimanickam R 2019 Patterns of expression of sperm and seminal plasma microRNAs in boar semen. Theriogenology 125 87-92. (https://doi.org/10.1016/j.theriogenology.2018.10.021)

Keerthikumar S, Chisanga D, Ariyaratne D, AI Saffar H, Anand S, Zhao K, Samuel M, Pathan M, Jois M, Chilamkurti N et al. 2016 ExoCarta: a web-based compendium of exosomal cargo. Journal of Molecular Biology 428 688-692. (https://doi.org/10.1016/j.jmb.2015.09.019)

Khatun M, Kaur S, Kanchan \& Mukhopadhyay CS 2013 Subfertility problems leading to disposal of breeding bulls. Asian-Australasian Journal of Animal Sciences 26 303-308. (https://doi.org/10.5713/ ajas.2012.12413)

Krawetz SA, Kruger A, Lalancette C, Tagett R, Anton E, Draghici S \& Diamond MP 2011 A survey of small RNAs in human sperm. Human Reproduction 26 3401-3412. (https://doi.org/10.1093/humrep/der329)

Li P, Kaslan M, Lee SH, Yao J \& Gao Z 2017 Progress in exosome isolation techniques. Theranostics 7 789-804. (https://doi.org/10.7150/ thno.18133)

Liebers R, Rassoulzadegan M \& Lyko F 2014 Epigenetic regulation by heritable RNA. PLoS Genetics 10 e1004296. (https://doi.org/10.1371/ journal.pgen.1004296)

Mcgraw LA, Suarez SS \& Wolfner MF 2015 On a matter of seminal importance. BioEssays $37 \quad 142-147 . \quad$ (https://doi.org/10.1002/ bies.201400117)

Memczak S, Jens M, Elefsinioti A, Torti F, Krueger J, Rybak A, Maier L, Mackowiak SD, Gregersen LH, Munschauer M et al. 2013 Circular RNAs are a large class of animal RNAs with regulatory potency. Nature 495 333-338. (https://doi.org/10.1038/nature11928)

Memczak S, Papavasileiou P, Peters O \& Rajewsky N 2015 Identification and characterization of circular RNAs as a new class of putative biomarkers in human blood. PLOS ONE 10 e0141214. (https://doi. org/10.1371/journal.pone.0141214)

Miller D 2015 Confrontation, consolidation, and recognition: the oocyte's perspective on the incoming sperm. Cold Spring Harbor Perspectives in Medicine 5 a023408. (https://doi.org/10.1101/cshperspect.a023408)

Montjean D, De La Grange P, Gentien D, Rapinat A, Belloc S, CohenBacrie P, Menezo Y \& Benkhalifa M 2012 Sperm transcriptome profiling in oligozoospermia. Journal of Assisted Reproduction and Genetics 29 3-10. (https://doi.org/10.1007/s10815-011-9644-3)

Nixon B, Stanger SJ, Mihalas BP, Reilly JN, Anderson AL, Tyagi S, Holt JE \& McLaughlin EA 2015a The microRNA signature of mouse spermatozoa is substantially modified during epididymal maturation. Biology of Reproduction 93 91. (https://doi.org/10.1095/biolreprod.115.132209)

Nixon B, Stanger SJ, Mihalas BP, Reilly JN, Anderson AL, Dun MD, Tyagi S, Holt JE, McLaughlin EA 2015b Next generation sequencing analysis reveals segmental patterns of microRNA expression in mouse epididymal epithelial cells. PLOS ONE 10 e0135605. (https://doi.org/10.1371/ journal.pone.0135605)

Ntostis P, Carter D, Iles D, Huntriss Jd, Tzetis M \& Miller D 2017 Potential sperm contributions to the murine zygote predicted by in silico analysis. Reproduction 154 777-788. (https://doi.org/10.1530/REP-17-0097)

Oliva R 2006 Protamines and male infertility. Human Reproduction Update 12 417-435. (https://doi.org/10.1093/humupd/dml009)

Pantano L, Jodar M, Bak M, Ballescà JL, Tommerup N, Oliva R \& Vavouri T 2015 The small RNA content of human sperm reveals pseudogene- 
derived piRNAs complementary to protein-coding genes. RNA 21 1085-1095. (https://doi.org/10.1261/rna.046482.114)

Platts AE, Dix DJ, Chemes HE, Thompson KE, Goodrich R, Rockett JC, Rawe VY, Quintana S, Diamond MP, Strader LF et al. 2007 Success and failure in human spermatogenesis as revealed by teratozoospermic RNAs. Human Molecular Genetics 16 763-773. (https://doi.org/10.1093/ $\mathrm{hmg} / \mathrm{ddm}$ 012)

Ramasamy R, Chiba K, Butler P \& Lamb DJ 2015 Male biological clock: a critical analysis of advanced paternal age. Fertility and Sterility $\mathbf{1 0 3}$ 1402-1406. (https://doi.org/10.1016/j.fertnstert.2015.03.011)

Rando OJ 2012 Daddy issues: paternal effects on phenotype. Cell $\mathbf{1 5 1}$ 702-708. (https://doi.org/10.1016/j.cell.2012.10.020)

Rassoulzadegan M, Grandjean V, Gounon P, Vincent S, Gillot I \& Cuzin F 2006 RNA-mediated non-Mendelian inheritance of an epigenetic change in the mouse. Nature 441 469-474. (https://doi.org/10.1038/ nature04674)

Robertson SA 2005 Seminal plasma and male factor signalling in the female reproductive tract. Cell and Tissue Research 322 43-52. (https:// doi.org/10.1007/s00441-005-1127-3)

Robertson SA \& Sharkey DJ 2016 Seminal fluid and fertility in women. Fertility and Sterility 106 511-519. (https://doi.org/10.1016/j. fertnstert.2016.07.1101)

Rodgers AB, Morgan CP, Bronson SL, Revello S \& Bale TL 2013 Paternal stress exposure alters sperm microRNA content and reprograms offspring HPA stress axis regulation. Journal of Neuroscience 33 9003-9012. (https://doi.org/10.1523/JNEUROSCI.0914-13.2013)

Sassone-Corsi P 2002 Unique chromatin remodeling and transcriptional regulation in spermatogenesis. Science 296 2176-2178. (https://doi. org/10.1126/science.1070963)

Schagdarsurengin U \& Steger K 2016 Epigenetics in male reproduction: effect of paternal diet on sperm quality and offspring health. Nature Reviews: Urology 13 584-595. (https://doi.org/10.1038/nrurol.2016.157)

Schuster A, Tang C, Xie Y, Ortogero N, Yuan S \& Yan W 2016 SpermBase: a database for sperm-borne RNA contents. Biology of Reproduction $\mathbf{9 5}$ 99-99. (https://doi.org/10.1095/biolreprod.116.142190)

Selvaraju S, Parthipan S, Somashekar L, Kolte AP, Krishnan Binsila B, Arangasamy A \& Ravindra JP 2017 Occurrence and functional significance of the transcriptome in bovine (Bos taurus) spermatozoa. Scientific Reports 7 42392. (https://doi.org/10.1038/srep42392)

Sendler E, Johnson GD, Mao S, Goodrich RJ, Diamond MP, Hauser R \& Krawetz SA 2013 Stability, delivery and functions of human sperm RNAs at fertilization. Nucleic Acids Research 41 4104-4117. (https:// doi.org/10.1093/nar/gkt132)

Sharma U, Conine CC, Shea JM, Boskovic A, Derr AG, Bing XY, Belleannee C, Kucukural A, Serra RW, Sun F et al. 2016 Biogenesis and function of tRNA fragments during sperm maturation and fertilization in mammals. Science 351 391-396. (https://doi.org/10.1126/science. aad6780)

Sharma U, Sun F, Conine CC, Reichholf B, Kukreja S, Herzog VA, Ameres SL \& Rando OJ 2018 Small RNAs are trafficked from the epididymis to developing mammalian sperm. Developmental Cell $\mathbf{4 6}$ 481-494.e6. (https://doi.org/10.1016/j.devcel.2018.06.023)

Spadafora C 2017 Sperm-mediated transgenerational inheritance. Frontiers in Microbiology 8 2401. (https://doi.org/10.3389/fmicb.2017.02401)

Suliman Y, Becker F \& Wimmers K 2018 Implication of transcriptome profiling of spermatozoa for stallion fertility. Reproduction, Fertility, and Development 30 1087-1098. (https://doi.org/10.1071/RD17188)
Sullivan R \& Saez F 2013 Epididymosomes, prostasomes and liposomes; their role in mammalian male reproductive physiology. Reproduction 146 R21-R35. (https://doi.org/10.1530/REP-13-0058)

Szabo L \& Salzman J 2016 Detecting circular RNAs: bioinformatic and experimental challenges. Nature Reviews. Genetics 17 679-692. (https:// doi.org/10.1038/nrg.2016.114)

Thomou T, Mori MA, Dreyfuss JM, Konishi M, Sakaguchi M, Wolfrum C, Rao TN, Winnay JN, Garcia-Martin R, Grinspoon SK et al. 2017 Adipose-derived circulating miRNAs regulate gene expression in other tissues. Nature 542 450-455. (https://doi.org/10.1038/nature21365)

Tuorto F, Herbst F, Alerasool N, Bender S, Popp O, Federico G, Reitter S, Liebers R, Stoecklin G, Gröne HJ et al. 2015 The tRNA methyltransferase Dnmt2 is required for accurate polypeptide synthesis during haematopoiesis. EMBO Journal 34 2350-2362. (https://doi. org/10.15252/embj.201591382)

Vassoler FM, White SL, Schmidt HD, Sadri-Vakili G \& Pierce RC 2013 Epigenetic inheritance of a cocaine-resistance phenotype. Nature Neuroscience 16 42-47. (https://doi.org/10.1038/nn.3280)

Vilagran I, Yeste M, Sancho S, Castillo J, Oliva R \& Bonet S 2015 Comparative analysis of boar seminal plasma proteome from different freezability ejaculates and identification of fibronectin 1 as sperm freezability marker. Andrology 3 345-356. (https://doi.org/10.1111/ andr.12009)

Vojtech L, Woo S, Hughes S, Levy C, Ballweber L, Sauteraud RP, Strobl J, Westerberg K, Gottardo R, Tewari M et al. 2014 Exosomes in human semen carry a distinctive repertoire of small non-coding RNAs with potential regulatory functions. Nucleic Acids Research 42 7290-7304. (https://doi.org/10.1093/nar/gku347)

Watkins AJ, Dias I, Tsuro H, Allen D, Emes RD, Moreton J, Wilson R, Ingram RJM \& Sinclair KD 2018 Paternal diet programs offspring health through sperm- and seminal plasma-specific pathways in mice. PNAS 115 10064-10069. (https://doi.org/10.1073/pnas.1806333115)

Yoda A, Oda S, Shikano T, Kouchi Z, Awaji T, Shirakawa H, Kinoshita K \& Miyazaki S 2004 Ca2+oscillation-inducing phospholipase C zeta expressed in mouse eggs is accumulated to the pronucleus during egg activation. Developmental Biology 268 245-257. (https://doi. org/10.1016/j.ydbio.2003.12.028)

Yuan S, Schuster A, Tang C, Yu T, Ortogero N, Bao J, Zheng H \& Yan W 2016 Sperm-borne miRNAs and endo-siRNAs are important for fertilization and preimplantation embryonic development. Development 143 635-647. (https://doi.org/10.1242/dev.131755)

Zeybel M, Hardy T, Wong YK, Mathers JC, Fox CR, Gackowska A, Oakley F, Burt AD, Wilson CL, Anstee QM et al. 2012 Multigenerational epigenetic adaptation of the hepatic wound-healing response. Nature Medicine 18 1369-1377. (https://doi.org/10.1038/nm.2893)

Zhang X, Gao F, Fu J, Zhang P, Wang Y \& Zeng X 2017 Systematic identification and characterization of long non-coding RNAs in mouse mature sperm. PLOS ONE 12 e0173402. (https://doi.org/10.1371/ journal.pone.0173402)

Received 19 December 2018

First decision 24 January 2019

Revised manuscript received 29 April 2019

Accepted 7 May 2019 